\title{
BMJ Open Cross-sectional and prospective follow- up study to detect early signs of cardiac dysfunction in obesity: protocol of the CARDIOBESE study
}

\author{
Sanne M Snelder, ${ }^{1}$ Lotte E de Groot - de Laat, ${ }^{2}$ L Ulas Biter, ${ }^{3}$ \\ Manuel Castro Cabezas, ${ }^{4}$ Gert-Jan van de Geijn, ${ }^{5}$ Erwin Birnie, ${ }^{6,7}$ \\ Bianca Boxma - de Klerk, ${ }^{6}$ René A Klaassen, ${ }^{8}$ Felix Zijlstra, ${ }^{9}$ Bas M van Dalen ${ }^{1,9}$
}

To cite: Snelder SM, de Groot - de Laat LE, Biter LU, et al. Cross-sectional and prospective follow-up study to detect early signs of cardiac dysfunction in obesity: protocol of the CARDIOBESE study. BMJ Open 2018;8:e025585. doi:10.1136/ bmjopen-2018-025585

- Prepublication history and additional material for this paper are available online. To view these files, please visit the journal online (http://dx.doi. org/10.1136/bmjopen-2018025585).

Received 24 July 2018 Revised 22 October 2018 Accepted 25 0ctober 2018

Check for updates

(C) Author(s) (or their employer(s)) 2018. Re-use permitted under CC BY-NC. No commercial re-use. See rights and permissions. Published by BMJ.

For numbered affiliations see end of article.

Correspondence to

Dr Bas M van Dalen;

b.vandalen@franciscus.nl

\section{ABSTRACT}

Introduction In view of the increasing occurrence of both obesity and heart failure, a growing overlap of these two clinical entities in the near future is expected. Significant advances in our understanding of the pathophysiological consequences of obesity for the cardiovascular system have been made over the past two decades. However, to optimise management and treatment of obesity patients, further research is required to improve early identification of cardiac dysfunction in obesity and to gain insight in the underlying pathophysiology. The CARdiac Dysfunction In OBesity - Early Signs Evaluation (CARDIOBESE) study has been designed to address these issues.

Methods and analysis CARDIOBESE is a cross-sectional multicentre study of 100 obesity patients scheduled for bariatric surgery (body mass index (BMI) $\geq 35 \mathrm{~kg} /$ $\mathrm{m}^{2}$ ) without known cardiovascular disease, and 50 agematched and gender-matched non-obese controls (BMI $<30 \mathrm{~kg} / \mathrm{m}^{2}$ ). Echocardiography, blood and urine biomarkers and Holter monitoring will be used to identify parameters that are able to show cardiac dysfunction at a very early stage in obesity patients (primary objective). Furthermore, a prospective follow-up study of obesity patients before and 1 year after bariatric surgery will be done to gain insight in the pathophysiology of obesity causing cardiac dysfunction (secondary objective).

Ethics and dissemination The study was approved by the Medical Ethics Committee Toetsingscommissie Wetenschappelijk Onderzoek Rotterdam e.o. (TWOR). Inclusion of patients and controls is almost complete. Analyses of the investigations are currently being performed, and dissemination through peer-reviewed publications and conference presentations is expected from the first quarter of 2019. By identifying early markers of cardiac dysfunction in obesity, and by understanding the underlying pathophysiology of the abnormalities of these markers, the CARDIOBESE study may provide guidance for risk stratification, monitoring and treatment strategies for obesity patients.

\section{INTRODUCTION}

In view of the increasing occurrence of both obesity and heart failure, a growing overlap of
Strengths and limitations of this study

- The CARdiac Dysfunction In OBesity - Early Signs Evaluation (CARDIOBESE) study will be the first study in which (speckle tracking) echocardiography, blood and urine biomarkers and Holter monitoring will be combined in a cohort of obesity patients and nonobese controls in order to identify subclinical cardiac dysfunction in obesity patients (primary objective).

- Relating findings of the diagnostic techniques for assessment of cardiac dysfunction used in the CARDIOBESE study to specific features of obesity and by comparing results in obesity patients before and 1 year after bariatric surgery may help to gain insight in the pathophysiology of obesity causing cardiac dysfunction (secondary objective).

- A multidisciplinary approach with cardiologists, surgeons, internists and clinical epidemiologists being involved in the design and execution of the CARDIOBESE study will warrant optimal results and interpretation of the data.

- Only including obesity patients scheduled for bariatric surgery may potentially lead to selection bias, preventing reliable extrapolation of results to all obesity patients.

these two clinical entities in the near future is expected. ${ }^{1-3}$ A body mass index (BMI) $\geq 30 \mathrm{~kg}$ / $\mathrm{m}^{2}$ worsens the prognosis of patients with cardiovascular disease and doubles the lifetime risk of developing heart failure. Significant advances in our understanding of the pathophysiological consequences of obesity for the cardiovascular system have been made over the past two decades. ${ }^{45}$ Obesity is associated with diabetes mellitus, dyslipidaemia and hypertension. However, the onset of heart failure in obesity cannot be fully explained by the presence of these traditional cardiac risk factors. ${ }^{6}$ Also, BMI may not be the optimal parameter to reflect increased cardiovascular risk in obesity. ${ }^{7}$ 
Present-day guidelines recommend screening of obesity patients on presence of cardiac risk factors and inclusion of obesity patients in cardiovascular rehabilitation programmes directed to reduce body weight and increase physical activity, thereby improving cardiac risk factors. ${ }^{5}$ The enormous and still growing prevalence of obesity warrants efficient screening of obesity patients with the highest need for such further risk assessment, follow-up and treatment. Current knowledge on the role of obesity in causing cardiac dysfunction is insufficient to optimally develop such strategies for obesity patients.

The aim of the CARdiac Dysfunction In OBesity Early Signs Evaluation (CARDIOBESE) study is to identify subclinical cardiac dysfunction in obesity patients by echocardiography, blood and urine tests and/or Holter monitoring (primary objective).

Bariatric surgery has proven to be a successful therapy for severe obese patients, both regarding weight loss and reduction of traditional cardiac risk factors. ${ }^{8}$ Relating findings of the diagnostic techniques for assessment of cardiac dysfunction used in the CARDIOBESE study to specific features of obesity and by comparing results in obesity patients before and 1year after bariatric surgery may help to gain insight in the pathophysiology of obesity causing cardiac dysfunction (secondary objective).

To the best of our knowledge, the CARDIOBESE study will be the first study in which (speckle tracking) echocardiography, blood and urine biomarkers and Holter monitoring will be combined in a cohort of obesity patients and non-obese controls.

\section{METHODS AND ANALYSIS}

\section{Study design}

Recruitment and inclusion of 100 consecutive obesity patients will take place at the bariatric surgery outpatient clinics of the Franciscus Gasthuis \& Vlietland (75 patients) and Maasstad Ziekenhuis (25 patients). Fifty non-obese controls will be recruited using advertisements in a local newspaper or will be personnel recruited from the participating hospitals or family members or friends of personnel. Cardiologists of the Erasmus University Medical Centre with extensive expertise on early detection of cardiac dysfunction were involved in the design of the study and will be assisting in data analysis.

\section{Primary objective}

A cross-sectional study of obesity patients scheduled for bariatric surgery and age-matched and gender-matched non-obese controls will be performed to quantify the proportion of early signs of cardiac dysfunction in obesity patients and to determine if obesity patients have an elevated prevalence of cardiac dysfunction. Conventional and advanced echocardiography will be performed, blood and urine samples will be collected and a Holter monitor will be affixed for 24 hours heart rhythm registration (figure 1).

\section{Secondary objective}

A prospective follow-up study of the obesity patients undergoing bariatric surgery will be performed to gain insight in the pathophysiology of obesity causing cardiac dysfunction (figure 1). The aforementioned diagnostic techniques will be repeated 1 year after bariatric surgery. Before-after changes in parameters of cardiac structure and function (table 1) will be related to before-after changes in features of obesity (table 2).

The objective of the CARDIOBESE study is not to investigate specific effects of bariatric surgery. To fulfil the secondary objective, we also could have chosen a conservative approach for weight loss (diet and exercise
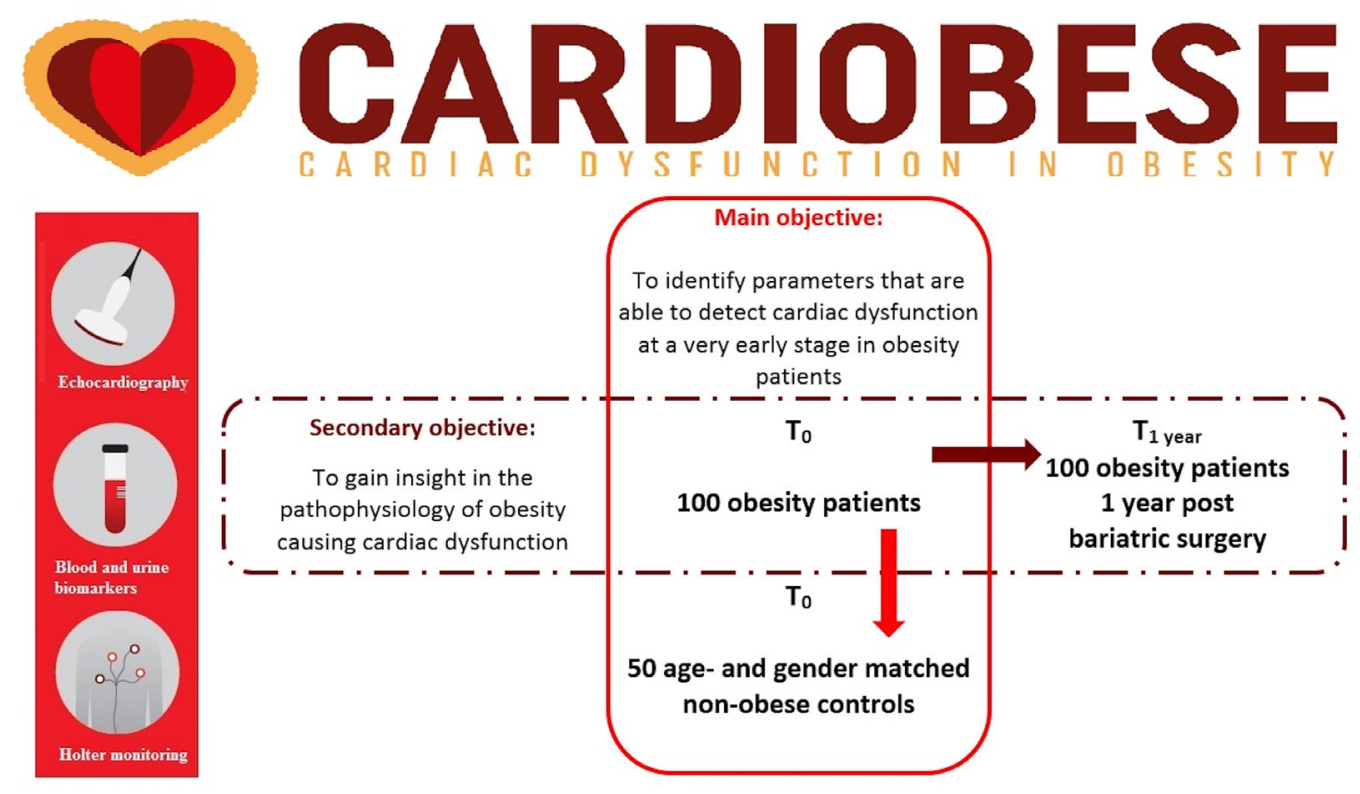

Figure 1 Overview of the design of the CARDIOBESE study. CARDIOBESE, CARdiac Dysfunction In OBesity - Early Signs Evaluation. 


\begin{tabular}{lll}
\hline Table 1 & Parameters of cardiac structure and function \\
\hline Echocardiography & Holter monitoring & $\begin{array}{l}\text { Blood and urine } \\
\text { biomarkers }\end{array}$ \\
\hline LV ejection fraction & $\begin{array}{l}\text { Premature atrial } \\
\text { beats }\end{array}$ & $\begin{array}{l}\text { High-sensitive } \\
\text { troponin I }\end{array}$ \\
\hline LV diastolic function & $\begin{array}{l}\text { Premature } \\
\text { ventricular beats }\end{array}$ & $\begin{array}{l}\text { Brain natriuretic } \\
\text { peptide (BNP) }\end{array}$ \\
E/Em & $\begin{array}{l}\text { Atrial fibrillation } \\
\text { Septal Em }\end{array}$ & $\begin{array}{l}\text { Supraventricular } \\
\text { tachycardia }\end{array}$ \\
\hline Lateral Em & $\begin{array}{l}\text { Ventricular } \\
\text { tachycardia }\end{array}$ & \\
Left atrial volume & $\begin{array}{l}\text { Heart rate } \\
\text { variability }\end{array}$ & \\
index &
\end{tabular}

\begin{tabular}{lll}
$\begin{array}{l}\text { LV mass (area-length } \\
\text { method) }\end{array}$ & SDNN \\
\hline TAPSE & SDNN index & \\
$\begin{array}{l}\text { Pulsed tissue } \\
\text { Doppler S wave } \\
\text { tricuspid annulus }\end{array}$ & rMSSD & \\
$\begin{array}{l}\text { Global systolic LV } \\
\text { strain/strain rate* }\end{array}$ & PNN50 & \\
$\begin{array}{l}\text { Diastolic strain rate, } \\
\text { early peak and late } \\
\text { peak* }\end{array}$ & Triangle & \\
LV twist $†$ & HF(norm) & \\
& LF(norm) & \\
& VLF & $\begin{array}{l}\text { Other biomarkers } \\
\text { will be chosen in a } \\
\text { later phase. }\end{array}$ \\
\hline
\end{tabular}

*Longitudinal, circumferential and radial strain will be measured. †Peak systolic twist/twist velocity, peak diastolic untwist velocity and untwisting rate will be measured.

$\mathrm{E} / \mathrm{Em}$, ratio of peak early left ventricular filling velocity $(\mathrm{E})$ over average septal and lateral mitral annulus early diastolic wave velocity (Em); HF(norm), high frequency normalised; LF(norm), low frequency normalised; LV, left ventricular; PNN50, percentage of successive normal sinus RR intervals $>50 \mathrm{~ms}$; rMSSD, root mean square of the successive normal sinus RR interval difference; SDNN, SD of all NN intervals; SDNN index, mean of the SD of all NN intervals for all $5 \mathrm{~min}$ segments of the entire recording; TAPSE, tricuspid annular plane systolic excursion; Triangle, number of all NN intervals/maximum number; VLF, very low frequency normalised.

programme) or study the effects of naturally occurring changes in weight. In the CARDIOBESE study, bariatric surgery is just used as an efficient method to rapidly induce significant metabolic improvement and weight loss. By studying these changes and trying to relate them to improvement in cardiac function, we expect to gain insight in the pathophysiology of obesity causing cardiac dysfunction. In this context, for the secondary objective, the obesity patient can be compared with his or her own baseline values and therefore be his or her own control.

\section{Study population}

Inclusion criteria

Patients: BMI $\geq 35 \mathrm{~kg} / \mathrm{m}^{2}$, scheduled for bariatric surgery, aged 35-65 years and written informed consent.

Controls: BMI $<30 \mathrm{~kg} / \mathrm{m}^{2}$, age $35-65$ years and written informed consent.

\section{Exclusion criteria}

Patients and controls: history of cardiovascular disease.

\section{Endpoints}

The main study parameter is the proportion of patients/ controls with any sign of cardiac dysfunction as assessed by either echocardiography, blood/urine biomarkers or Holter monitoring (table 1). An early sign of cardiac dysfunction is considered to be present when a studied parameter is significantly different from a well-defined cut-off value. ${ }^{910}$ When such a cut-off value is not available, a studied parameter is considered to be an early sign of cardiac dysfunction when significantly different between obesity patients and non-obese controls. Secondary endpoints are: change in the proportion of obesity patients with any sign of cardiac dysfunction between study onset and 1 year after bariatric surgery and changes in cardiac dysfunction parameters in obesity patients undergoing bariatric surgery between study onset and 1 year after surgery.

\section{Sample size calculation}

The fact that the combination of parameters that we will use to identify subclinical cardiac dysfunction has not been investigated in obesity before complicates a well-defined and evidence-based sample size calculation.

A conservative estimate would be that cardiac dysfunction based on conventional echocardiography is present in $20 \%$ of obesity patients and $2.5 \%$ of age-matched and gender-matched non-obese controls. ${ }^{11}$ Given these estimates, to be able to reject the null hypothesis that cardiac dysfunction rates are equal between patients and controls, at least 97 obesity patients and 49 non-obese controls have to be included in the analysis (alpha: 0.05 (two sided), power: 0.80, 2:1 ratio of patients:controls). The use of more sensitive techniques in the CARDIOBESE study may increase the proportion of non-obese controls with an early sign of cardiac dysfunction. Nevertheless, the proportion of obesity patients with an early sign of cardiac dysfunction is expected to increase even more, assuring that the previous sample size calculation will still suffice.

\section{Study procedures \\ Echocardiography}

Two-dimensional greyscale harmonic images will be obtained in the left lateral decubitus position using a commercially available ultrasound system (EPIQ 7, Philips, Best, The Netherlands), equipped with a broadband $(1-5 \mathrm{MHz}) \mathrm{X} 5-1$ transducer. All acquisitions and measurements will be performed according to current guidelines. ${ }^{9} 1012$ 
Table 2 General characteristics and obesity parameters

\begin{tabular}{lllll}
\hline Physical examination & Comorbidity & Medication & Laboratory tests & \\
\hline Body mass index & Diabetes mellitus & Beta blocker & CRP & Transferrin \\
Waist circumference & Hypertension & ACE inhibitor & HbA1C & Ferritin \\
Systolic BP & Hyperlipidaemia & ARB & TSH & Active Vitamin B12 \\
Diastolic BP & Current smoking & Diuretic & HDL-cholesterol & Folic acid \\
Heart rate & COPD & Calcium-channel antagonist & LDL-cholesterol & Albumin \\
& OSAS & Statin & Triglycerides & Magnesium \\
& Arthralgia & Aspirin & Total cholesterol & Vitamin B1 \\
& Alcohol abuse & Other antiplatelet & Lipoprotein A & Vitamin B6 \\
& Drug abuse & Insulin & Apo B100 & Vitamin D \\
& & Oral antidiabetics & Sodium & Haemoglobin \\
& & Anti-inflammatory agents & Potassium & Haematocrit \\
& & & Calcium & Erythrocytes \\
& & & Creatinine & MCV \\
\hline
\end{tabular}

Comorbidity as reported by the patient or the general practitioner.

ALAT, alanine amino-transferase; ARB, angiotensin receptor blocker; BP, blood pressure; COPD, chronic obstructive pulmonary disease; CRP, $\mathrm{C}$ reactive protein; $\mathrm{HbA1c}$, Glycosylated Hemoglobin; HDL, high-density lipoprotein; LDL, low-density lipoprotein; MDRD, modification of diet in renal disease; OSAS, obstructive sleep apnoea syndrome; TSH, Thyroid-stimulating hormone.

Interobserver and intraobserver, and test-retest reproducibility of the assessment of cardiac dimensions and function in obesity by echocardiography will be investigated in a substudy.

\section{Blood and urine biomarkers}

Blood and urine samples will be taken both for the study and as part of regular care. Urine supernatant, serum, citrate plasma and EDTA plasma will be prepared by centrifugation at $4^{\circ} \mathrm{C}$ and frozen in aliquots at $-80^{\circ} \mathrm{C}$ for future analysis within 2 hours. In addition to the regular care path blood tests, high sensitive troponin I, C reactive protein and brain natriuretic peptide will be determined immediately. Other biomarkers may be selected later and can subsequently be determined from the stored blood and/or urine samples.

\section{Holter monitoring}

Heart rhythm will be recorded for 24 consecutive hours using a portable digital recorder (GE SEER Light, Chicago, Illinois, USA). The digital recorder will be connected using stickers that are placed on the chest.

\section{Statistical analysis}

The proportion of obesity patients/non-obese controls with any sign of cardiac dysfunction will be compared as prevalence difference $(95 \% \mathrm{CI})$ and prevalence ratio (95\% CI). The unpaired Student's t-test for continuous variables will be used to compare parameters with normal distributions, the non-parametric Mann-Whitney U test for continuous parameters with skewed distributions and the $\chi^{2}$ test/Fisher's exact test for categorical variables. Statistical significance is considered as a two-tailed $\mathrm{p}$ value
$<0.05$. Bonferroni correction for multiple testing will be applied. For each individual test parameter, presence/ absence of a sign of cardiac dysfunction will be evaluated using multiple linear and logistic regression analysis (method: backwards stepwise analysis). Covariates to be included are the matching factors (age and gender), group definition (obesity patient/non-obese control), baseline characteristics considered to be potentially related to cardiac dysfunction (continuous variables such as BMI and body weight and categorical variables such as diabetes, hypertension, hyperlipidaemia and smoking) and other studied parameters identified to be significantly different between obesity patients and healthy volunteers by univariate analysis.

The change in the proportion of obesity patients with any sign of cardiac dysfunction between study onset and 1 year after bariatric surgery will be tested with the McNemar test. Multiple logistic regression analysis will be used to investigate which parameters contribute to the likelihood of a sign of cardiac dysfunction at 1 year after bariatric surgery. Covariates to be included are the same as mentioned before. Changes in individual parameters of cardiac dysfunction between study onset and 1year after bariatric surgery will be studied using paired Student's t-test, the non-parametric Wilcoxon signed rank test and McNemar test. Statistical analyses will be performed with SPSS V.25.0 or higher.

\section{Patient and public involvement}

Before the finalisation of the protocol for the CARDIOBESE study, 25 obesity patients that visited the outpatient clinic for screening for bariatric surgery were asked whether they would be willing to undergo some 
extra tests (echocardiogram, extra blood samples and Holter monitoring) when asked to participate in a study to investigate early signs of cardiac dysfunction in obesity. Without exception patients confirmed willingness to potentially participate. Patients recognised the importance of such a study and a majority of patients even reported that fear of developing heart disease was one of the major reasons to consider bariatric surgery.

On completion of the study, the results will be summarised in layman's terms and distributed to participants and patient support groups. We will also promote the transfer of knowledge to the general public (eg, including short, user-friendly articles/briefings in relevant newsletters, magazines and periodicals and user groups/forums).

\section{DISCUSSION}

Obesity is becoming a global epidemic. ${ }^{13}$ Beyond being related to an unfavourable cardiovascular risk factor profile, obesity also directly affects heart structure and function. ${ }^{14}$ However, proper clinical evaluation of obesity patients may be hampered by the morphology of the patient. ${ }^{15}$ Also, knowledge on the exact pathophysiology of obesity causing cardiac dysfunction is limited. ${ }^{16}$ The CARDIOBESE study has been designed to address these issues.

\section{Early signs of cardiac dysfunction in obesity Echocardiography}

It is well known that there is a relationship between obesity and left ventricular (LV) diastolic dysfunction (online supplementary appendix 1). However, the latest improvement in echocardiography regarding early recognition of cardiac dysfunction has been the development of speckle tracking echocardiography. Each region of the myocardium has its own unique speckle pattern that remains stable enough to permit spatial and temporal image processing by dedicated software packages, allowing assessment of myocardial deformation parameters such as LV strain and twist, which are well-known measures of subtle LV dysfunction. ${ }^{1012} 17$

Speckle tracking echocardiography data in obesity patients are relatively scarce and only concern LV strain and not twist (online supplementary appendix 1). Although availability of speckle tracking echocardiography may still be limited, echo-machines from all wellknown vendors are currently routinely equipped with speckle tracking software. Also, the technique has been significantly improved the past decennium, and intervendor differences have been minimised, ${ }^{12}$ optimising clinical applicability. In the CARDIOBESE study, LV strain and twist will be thoroughly studied in obesity patients.

\section{Blood and urine biomarkers}

Focus in obesity research has mainly been on biomarkers of inflammation, insulin resistance and kidney/liver damage. Exploration of the value of blood and urine biomarkers for detection of subclinical cardiac dysfunction in obesity patients has been limited. There are some studies in which high-sensitive troponin $\mathrm{T}$ was measured in obesity patients but with conflicting results. ${ }^{18} 19$

Studies concerning natriuretic peptides in obesity patients without known cardiovascular disease demonstrated that higher BMI is associated with lower circulating natriuretic peptide concentrations (online supplementary appendix 1). ${ }^{20}{ }^{21}$ The mechanism of this inverse relationship is not fully understood. It is thought to be related to either decreased production or increased peripheral metabolism of natriuretic peptides. ${ }^{22}$ Despite its inverse relationship with BMI, natriuretic peptides do provide significant prognostic information regarding the risk of developing heart failure in obesity. ${ }^{23}$

In the CARDIOBESE study, blood and urine biomarkers will be compared with echocardiography and Holter monitoring parameters in order to assess the diagnostic value of the biomarkers and to better understand the underlying pathophysiology of changes in the concentration (or presence) of the biomarkers. Because of the rapid development of new blood and urine biomarkers of cardiac dysfunction, spare samples from each patient and control will be stored in order to choose optimal biomarkers at a later stage.

\section{Holter monitoring}

In community and population-based cohort studies, obesity has consistently emerged as a risk factor for atrial fibrillation. ${ }^{24}$ Identification of precursors of atrial fibrillation may lead to early detection of atrial fibrillation. Frequent premature atrial complexes are known to be associated with a risk of developing atrial fibrillation. ${ }^{25}$ Despite this, the usefulness of searching for atrial fibrillation or its electrical precursors as early markers of cardiac dysfunction in obesity has never been investigated. Therefore, this will be done in the CARDIOBESE study.

Obesity patients have an increased sympathetic nervous system activity shown by an increase in mean heart rate, whereas heart rate variability parasympathetic indicators are decreased. ${ }^{26}$ Since autonomic dysfunction may play a role in development of cardiac dysfunction, in the CARDIOBESE study parameters of heart rate variability will be investigated.

\section{Pathophysiology of cardiac dysfunction in obesity}

The pathophysiology of cardiac dysfunction in obesity is incompletely understood and most likely multifactorial. Myocardial lipotoxicity, thrombosis, altered endothelial function, compression by fat tissue, diastolic dysfunction, increased afterload and filling pressures may all play a role. ${ }^{27}$ Changes in cardiac parameters after bariatric surgery have been studied before, showing improvement of LV structure, LV diastolic function, LV global strain and strain rate, natriuretic peptide levels and heart rate variability (online supplementary appendix 1). However, in none of these studies information from echocardiography, blood and urine biomarkers and Holter monitoring have been combined. In the CARDIOBESE study, 
correlating findings of these different diagnostic techniques and comparing results before and 1year after bariatric surgery may help to gain insight in the pathophysiology of obesity causing cardiac dysfunction.

\section{Ethics and dissemination}

Inclusion of patients and controls is almost complete. CARDIOBESE enrolled 92 obesity patients between 1 January 2017 and 23 July 2018, and 46 non-obese controls between 20 November 2017 and 23 July 2018. Analyses of the investigations are currently being performed, and dissemination through peer-reviewed publications and conference presentations is expected from the first quarter of 2019. By identifying early markers of cardiac dysfunction in obesity, and by understanding the underlying pathophysiology of the abnormalities of these markers, the CARDIOBESE study may provide guidance for risk stratification, monitoring and treatment strategies for obesity patients.

\section{Author affiliations}

${ }^{1}$ Department of Cardiology, Franciscus Gasthuis \& Vlietland, Rotterdam, The Netherlands

${ }^{2}$ Department of Cardiology, Maasstad Ziekenhuis, Rotterdam, The Netherlands ${ }^{3}$ Department of Surgery, Franciscus Gasthuis \& Vlietland, Rotterdam, The Netherlands

${ }^{4}$ Department of Internal Medicine, Franciscus Gasthuis \& Vlietland, Rotterdam, The Netherlands

${ }^{5}$ Department of Clinical Chemistry, Franciscus Gasthuis \& Vlietland, Rotterdam, The Netherlands

${ }^{6}$ Franciscus Academy - Research Centre, Franciscus Gasthuis \& Vlietland, Rotterdam, The Netherlands

${ }^{7}$ Department of Obstetrics and Gynaecology, University Medical Centre Utrecht, Utrecht University, Rotterdam, The Netherlands

${ }^{8}$ Department of Surgery, Maasstad Ziekenhuis, Rotterdam, The Netherlands ${ }^{9}$ Department of Cardiology, The Thoraxcenter, Erasmus University Medical Centre, Rotterdam, The Netherlands

Contributors SMS: conception and design and drafting the manuscript. LEdG-dL, LUB, MCC, GJvdG and RAK: conception and design, and critical revision of the manuscript. EB and BB-dK: conception and design, statistical analysis and critical revision of the manuscript. FZ: conception and design, obtaining funding and supervising the work and critical revision of the manuscript. BMvD: conception and design, statistical analysis, obtaining funding and supervising the work, drafting the manuscript and critical revision of the manuscript.

Funding This work was supported by a grant from Stichting BeterKeten.

Competing interests None declared.

Patient consent Obtained.

Ethics approval The study was approved by the Medical Ethics Committee Toetsingscommissie Wetenschappelijk Onderzoek Rotterdam e.o. (TWOR).

Provenance and peer review Not commissioned; externally peer reviewed.

Open access This is an open access article distributed in accordance with the Creative Commons Attribution Non Commercial (CC BY-NC 4.0) license, which permits others to distribute, remix, adapt, build upon this work non-commercially, and license their derivative works on different terms, provided the original work is properly cited, appropriate credit is given, any changes made indicated, and the use is non-commercial. See: http://creativecommons.org/licenses/by-nc/4.0/.

\section{REFERENCES}

1. Lavie CJ, Sharma A, Alpert MA, et al. Update on obesity and obesity paradox in heart failure. Prog Cardiovasc Dis 2016;58:393-400.

2. Webber L, Divajeva D, Marsh T, et al. The future burden of obesityrelated diseases in the 53 WHO European-Region countries and the impact of effective interventions: a modelling study. BMJ Open 2014;4:e004787.

3. Horwich TB, Fonarow GC, Clark AL. Obesity and the obesity paradox in heart failure. Prog Cardiovasc Dis 2018;61:151-6.

4. Bui AL, Horwich TB, Fonarow GC. Epidemiology and risk profile of heart failure. Nat Rev Cardiol 2011;8:30-41.

5. Badimon L, Bugiardini R, Cenko E, et al. Position paper of the European Society of Cardiology-working group of coronary pathophysiology and microcirculation: obesity and heart disease. Eur Heart J 2017;38:1951-8.

6. Ndumele CE, Matsushita K, Lazo M, et al. Obesity and subtypes of incident cardiovascular disease. J Am Heart Assoc 2016;5.

7. Azhari Z, Ismail MD, Zuhdi ASM, et al. Association between body mass index and outcomes after percutaneous coronary intervention in multiethnic South East Asian population: a retrospective analysis of the Malaysian National Cardiovascular Disease DatabasePercutaneous Coronary Intervention (NCVD-PCI) registry. BMJ Open 2017;7:e017794.

8. Sjöström L, Lindroos AK, Peltonen M, et al. Lifestyle, diabetes, and cardiovascular risk factors 10 years after bariatric surgery. N Engl J Med 2004;351:2683-93.

9. Lang RM, Badano LP, Mor-Avi V, et al. Recommendations for cardiac chamber quantification by echocardiography in adults: an update from the american society of echocardiography and the european association of cardiovascular imaging. Eur Heart J Cardiovasc Imaging 2015;16:233-71.

10. Nagueh SF, Smiseth OA, Appleton CP, et al. Recommendations for the evaluation of left ventricular diastolic function by echocardiography: an update from the american society of echocardiography and the european association of cardiovascular imaging. Eur Heart J Cardiovasc Imaging 2016;17:1321-60.

11. Pascual M, Pascual DA, Soria F, et al. Effects of isolated obesity on systolic and diastolic left ventricular function. Heart 2003;89:1152-6.

12. Voigt JU, Pedrizzetti G, Lysyansky P, et al. Definitions for a common standard for 2D speckle tracking echocardiography: consensus document of the EACVI/ASE/Industry Task Force to standardize deformation imaging. Eur Heart J Cardiovasc Imaging 2015;16:1-11.

13. Engeland A, Bjørge T, Søgaard AJ, et al. Body mass index in adolescence in relation to total mortality: 32-year followup of 227,000 Norwegian boys and girls. Am J Epidemiol 2003:157:517-23.

14. Alpert MA, Karthikeyan $\mathrm{K}$, Abdullah $\mathrm{O}$, et al. Obesity and cardiac remodeling in adults: mechanisms and clinical implications. Prog Cardiovasc Dis 2018;61:114-23.

15. Piché ME, Poirier P, Lemieux I, et al. Overview of epidemiology and contribution of obesity and body fat distribution to cardiovascular disease: an update. Prog Cardiovasc Dis 2018;61:103-13.

16. Aune D, Sen A, Norat T, et al. Body mass index, abdominal fatness, and heart failure incidence and mortality: a systematic review and dose-response meta-analysis of prospective studies. Circulation 2016;133:639-49.

17. van Dalen BM, Tzikas A, Soliman OI, et al. Left ventricular twist and untwist in aortic stenosis. Int J Cardiol 2011;148:319-24.

18. Ndumele CE, Coresh J, Lazo M, et al. Obesity, subclinical myocardial injury, and incident heart failure. JACC Heart Fail 2014;2:600-7.

19. Siervo M, Ruggiero D, Sorice R, et al. Body mass index is directly associated with biomarkers of angiogenesis and inflammation in children and adolescents. Nutrition 2012;28:262-6.

20. Buckley LF, Canada JM, Del Buono MG, et al. Low NT-proBNP levels in overweight and obese patients do not rule out a diagnosis of heart failure with preserved ejection fraction. ESC Heart Fail 2018;5:372-8.

21. Meijers WC, Hoekstra T, Jaarsma T, et al. Patients with heart failure with preserved ejection fraction and low levels of natriuretic peptides. Neth Heart J 2016;24:287-95.

22. Shah Z, Wiley M, Sridhar AM, et al. Inverse correlation of venous brain natriuretic peptide levels with body mass index is due to decreased production. Cardiology 2017;137:159-66.

23. Ndumele CE, Matsushita $\mathrm{K}$, Sang $\mathrm{Y}$, et al. N-terminal pro-brain natriuretic peptide and heart failure risk among individuals with and without obesity: The Atherosclerosis Risk in Communities (ARIC) Study. Circulation 2016;133:631-8.

24. Frost L, Hune LJ, Vestergaard P. Overweight and obesity as risk factors for atrial fibrillation or flutter: the Danish Diet, Cancer, and Health Study. Am J Med 2005;118:489-95.

25. Acharya T, Tringali S, Bhullar M, et al. Frequent atrial premature complexes and their association with risk of atrial fibrillation. $A m \mathrm{~J}$ Cardiol 2015;116:1852-7.

26. Yadav RL, Yadav PK, Yadav LK, et al. Association between obesity and heart rate variability indices: an intuition toward cardiac autonomic alteration - a risk of CVD. Diabetes Metab Syndr Obes 2017:10:57-64. 
